\title{
PRODUKTIVITAS PADI DI PROVINSI SULAWESI SELATAN MENGGUNAKAN METODE MULTIDIMENSIONAL SCALING (MDS)
}

\author{
Nila Lestari ${ }^{i}$, Try Azisah Nurman ${ }^{\text {ii }}$, Khalilah Nurfadilah ${ }^{\text {iii }}$
}

\begin{abstract}
${ }^{i}$ Mahasiswa Universitas Islam Negeri Alauddin Makassar
ii Universitas Islam Negeri Alauddin Makassar,try.azisah@uin-alauddin.ac.id

iii Universitas Islam Negeri Alauddin Makassar
\end{abstract}

ABSTRAK, Penelitian ini membahas tentang produktivitas padi berdasarkan pengelompokan kabupaten/kota yang ada di Provinsi Sulawesi Selatan. Variabel produktivitas padi yang telah dikumpulkan akan memberikan informasi menggunakan metode Multidi mensional Scaling (MDS) dalam bentuk peta spasial. Analisis MDS adalah suatu teknik variabel ganda yang dapat digunakan untuk menentukan posisi suatu objek relatif terhadap objek lain berdasarkan penilaian kemi ripannya. Kedekatan objek ditentukan dari nilai stimulus coordinat serta kevalidan hasil dilihat dari nilai stress. hhasil analisis diperoleh 6 kelompok Kabupaten/Kota tersebut memiliki kemiripan produk tivitas padi berdasarkan variabel yang digunakan. Kelompok I adalah Kepulauan Selayar, Kabupaten Bantaeng, Kabupaten Jeneponto, Kabupaten Takalar, Kabupaten Sinjai, Kabupaten Pangkep, Kabupaten Soppeng, Kasil, bupaten Barru, Kabupaten Enrekang, Kabupaten Tana Toraja, Kabupaten Luwu Utara, Kabupaten Luwu Timur, Kabupaten Toraja Utara, Kota Parepare, dan Kota Palopo. Kelompok ini memiliki tingkat produktivitas padi yang sedang. Kelompok II adalah Kabupaten Bulukumba, Kabupaten Maros, dan Kabupaten Luwu. Kelompok ini memiliki tingkat produktivitas padi yang sedang. Kelompok III adalah Kabupaten Wajo, Kabupaten Sidrap, dan Kabupaten Pinrang. Kelompok ini memiliki tingkat produktivitas padi yang sedang. Kelompok IV adalah Kabupaten Gowa dengan tingkat produktivitas padi sedang. Kelompok V adalah Kabupaten Bone dengan tingkat produktivitas padi sedang. Kelompok VI adalah Kota Makassar dengan tingkat produktivitas padi rendah. Nilai stress yang dihasilkan adalah sebesar 0,01172 . Variabel yang mendukung produktivitas padi di provinsi Sulawesi Selatan adalah luas panen $\left(\mathrm{X}_{1}\right)$, puso padi $\left(\mathrm{X}_{2}\right)$, produksi padi $\left(\mathrm{X}_{4}\right)$, jumlah penduduk $\left(\mathrm{X}_{7}\right)$ dan jumlah rumah tangga $\left(\mathrm{X}_{8}\right)$.

Kata Kunci: Produktivitas padi, Multidimensional scaling, Stimulus coordinates,

\section{PENDAHULUAN}

Tingginya ketergantungan Indonesia terhadap impor beras dunia merupakan salah satu alasan mengapa upaya peningkatan produksi beras nasional melalui program intensifikasi dan ekstensifikasi perlu dilakukan. Selain adanya konversi lahan pertanian, ketersediaan gabah atau beras.
Untuk memahami atribut apa saja yang menunjang produktivitas padi di Provinsi Sulawesi Selatan dibutuhkan analisis tertentu. Atribut tersebut harus mampu menunjang produktivitas padi secara menyeluruh dan efektif yang akan dipetakan menurut Kabupaten/Kota yang memproduksi padi. Setelah pengelompokan kabupaten dilakukan maka diperoleh atribut yang berpengaruh terhadap produktivitas padi. Beberapa atribut yang berpengaruh terbagi ke dalam tiga kelompok yaitu segi ekonomi, segi ekologi dan segi sosial budaya. Ilmu statistika yang dapat digunakan dalam analisis yang dimaksud ialah analisis multivariat salah satunya adalah metode Multidimensional Scaling (MDS).

MDS merupakan suatu metode yang dapat memetakan data pengamatan dengan cara menentukan jarak titik-titik obyek yang dipetakan dan jarak tersebut adalah proporsi keragaman dari data yang berbentuk skala. Metode ini dapat menghasilkan pemetaan Kabupaten/Kota yang ada di Provinsi Sulawesi Selatan terhadap atribut produksi padi dan atribut yang berpengaruh terhadap produktivitas padi.

Tujuan dari tulisan ini adalah untuk memvisualisasikan produktivitas padi berdasarkan Kabupaten/Kota di Provinsi Sulawesi Selatan menggunakan metode $M D S$ serta mengetahui variabel produktivitas padi yang mendukung di Provinsi Sulawesi Selatan.

\section{TINJAUANPUSTAKA}

\section{ANALISIS MULTIVARIAT}

Analisis statistik multivariat merupakan metode statistik yang memungkinkan peneliti melakukan penelitian terhadap lebih dari dua variabel secara bersamaan. Dengan menggunakan teknik analisis ini maka peneliti dapat menganalisis pengaruh beberapa variabel 
terhadap variabel lainnya dalam waktu yang bersamaan.

Data dalam analisis multivariat dapat dinyatakan dalam bentuk matriks dimana jika terdapat $n$ baris dan $p$ kolom dengan bentuk umum digambarkan pada matriks $\boldsymbol{X}$ sebagai berikut:

$$
\boldsymbol{X}=\left[\begin{array}{cccccc}
x_{11} & x_{12} & \ldots & x_{1 j} & \ldots & x_{1 p} \\
x_{21} & x_{22} & \ldots & x_{2 j} & \ldots & x_{2 p} \\
\vdots & \vdots & & \vdots & & \vdots \\
x_{i 1} & x_{i 1} & \ldots & x_{i j} & \ldots & x_{i p} \\
\vdots & \vdots & & \vdots & & \vdots \\
x_{n 1} & x_{n 2} & \ldots & x_{n j} & \ldots & x_{n p}
\end{array}\right]
$$

dengan

$x_{i j} \quad$ : elemen dari matriks $\boldsymbol{X}$

$n \quad$ : banyaknya obyek

$p \quad$ : banyaknya variabel

\section{RUANG P EUCLIDEAN}

Jika $\mathrm{p}$ sebuah bilangan bulat positif, maka sebuah pasangan berurutan orde $\mathrm{p}$ adalah sebuah urutan dari $\mathrm{p}$ bilangan real $a_{1}, a_{2}, \ldots, a_{p}$. Himpunan semua pasangan berurutan $\mathrm{p}$ dinamakan ruang-p dan dinyatakan dengan $R_{p}$.

\section{KONSEP MATRIKS}

\section{Matriks simetrik}

Sebuah matriks $\boldsymbol{A}$ berukuran $n \times n$ dikatakan simetrik jika $\boldsymbol{A}^{T}=\boldsymbol{A}$.

$$
\boldsymbol{A}=\left[\begin{array}{ccc}
7 & 8 & -3 \\
8 & 0 & 1 \\
-3 & 1 & 9
\end{array}\right]
$$

\section{Nilai Eigen Dan Vektor Eigen}

Jika $\boldsymbol{A}$ adalah matriks $n \times n$, maka vektor tak nol dalam $R_{p}$ dinamakan vektor eigen (eigen vector) dari $\boldsymbol{A}$ jika $\boldsymbol{A} \overrightarrow{\boldsymbol{x}}$ adalah kelipatan skalar dari $\vec{x}$, yakni $\boldsymbol{A} \overrightarrow{\boldsymbol{x}}=\lambda \overrightarrow{\boldsymbol{x}}$

Untuk suatu skalar $\lambda$. Skalar $\lambda$ dinamakan nilai eigen (eigen value) dari $\boldsymbol{A}$ dan $\vec{x}$ dikatakan vector eigen yang bersesuaian dengan $\lambda$. Untuk mencari nilai eigen matriks $\boldsymbol{A}$ yang berukuran $n \times n$ maka dapat dituliskan $\boldsymbol{A} \overrightarrow{\boldsymbol{x}}=\lambda \overrightarrow{\boldsymbol{x}}$ sebagai $\boldsymbol{A} \overrightarrow{\boldsymbol{x}}=\lambda \boldsymbol{I} \overrightarrow{\boldsymbol{x}}$ atau secara ekivalen $(\lambda \boldsymbol{I}-\boldsymbol{A}) \overrightarrow{\boldsymbol{x}}=0$

\section{ANALISIS MULTIDIMENSIONAL \\ SCALLING Pengertian Multidimensional Scaling}

Analisis Multidimensional Scaling (MDS) adalah suatu teknik variabel ganda yang dapat digunakan untuk menentukan posisi suatu objek relatif terhadap objek lain berdasarkan penilaian kemiripannya. MDS disebut juga Perceptual Map. MDS berhubungan dengan pembuatan map untuk menggambarkan posisi sebuah objek dengan objek lainnya berdasarkan kemiripan objek-objek tersebut.

\section{Jarak Euclid (Euclidean Distance)}

Kemiripan antar objek diukur dengan menggunakan ukuran jarak. Beberapa ukuran jarak yang sering digunakan antara lain Euclidean distance, mahalanobis distance, Cityblock distance (Manhattan), dan lain-lain.

Ukuran proximity yang sering digunakan adalah fungsi Euclidean distance. Persamaan jarak Euclid dengan dimensi $n$ adalah :

$$
d_{i j}=\sqrt{\sum_{k=1}^{n}\left(x_{i k}-x_{j k}\right)^{2}}
$$

di mana

$d_{i j}=$ jarak dari stimulus ke- $i$ dan stimulus ke $-j$

$x_{i k}=$ nilai stimulus $i$ terhadap deskriptor ke- $k$

$x_{j k}=$ nilai stimulus $j$ terhadap deskriptor ke- $k$

$n=$ banyaknya deskriptor

\section{Stress}

Stress ialah ukuran ketidakcocokan (a lack of fit measure). Nilai stress mengindikasikan sebuah model baik atau tidak. Semakin tinggi nilai stress model semakin tidak cocok.

$$
\text { Stress }=\sqrt{\frac{\sum_{i, j}\left(d_{i j}-\hat{d}_{i j}\right)^{2}}{\sum_{i, j} d_{i j}^{2}}}
$$

di mana

$d_{i j}=$ jarak antara titik ke $i$ dan $j$

$\hat{d}_{i j}=$ disparaties dari transformasi

Menurut Kruskal, ukuran nilai stress adalah sebagai berikut :

Tabel 1 Kriteria nilai Stress

\begin{tabular}{|l|l|}
\hline \multicolumn{1}{|c|}{ Stress } & \multicolumn{1}{c|}{ Goodness offit } \\
\hline $20 \%$ & Poor \\
\hline $10 \%$ & Fair \\
\hline $5 \%$ & Good \\
\hline
\end{tabular}




\begin{tabular}{|l|l|}
\hline \multicolumn{1}{|c|}{ Stress } & \multicolumn{1}{c|}{ Goodness of fit } \\
\hline $2,5 \%$ & Excellent \\
\hline $0 \%$ & Perfect \\
\hline
\end{tabular}

\section{$R^{2}$}

$R^{2}=\mathrm{R}$ kuadrat ( $R$ square) ialah kuadrat dari koefisien korelasi yang menunjukkan proporsi varian dari skala optimal data, yang disumbangkan oleh prosedur penskalaan multidimensional ukuran kecocokan/ ketepatan (goodness of fit measure). Semakin besar nilai $R^{2}$ maka model yang dihasilkan semakin baik. Besarnya nilai $R^{2}$ dapat dihitung dengan persamaan: $R^{2}=\frac{b_{i}\left(\sum\left(x_{i}-\bar{x}\right)\left(y_{i}-\bar{y}\right)\right)}{\sum y_{i}^{2}-n \bar{y}^{2}}$

\section{Jenis Multidimensional Scaling}

Berdasarkan tipe data, Multidimensional scaling dibagi menjadi 2 (dua) jenis, yaitu Multidimensional scaling metrik dan Multidimensional scaling non-metrik.

MDS metrik mengasumsikan bahwa data adalah kuantitif (interval dan rasio). MDS metrik digunakan untuk menemukan himpunan titik dalam ruang dimensi $\mathrm{n}$ di mana masing-masing titik mewakili satu objek sehingga jarak antar titik adalah $d_{i j} \approx f\left(\delta_{i j}\right)$, dimana $f$ adalah fungsi monotonic parametric kontinu.

Diberikan Matriks $\boldsymbol{A}\left(\begin{array}{lll}n & x & n\end{array}\right)$ matriks jarak $\boldsymbol{D}=$ $\left(d_{i j}\right)$ adalah Euclidean distance jika untuk setiap titik $x_{1}, \cdots, x_{i j} \in R^{p} ; d_{i j}^{2}=\left(x_{i}-x_{j}\right)^{T}\left(x_{i}-x_{j}\right) . \boldsymbol{A}$ didefinisikan sebagai $\quad\left[\boldsymbol{A}_{\mathrm{ij}}\right]=a_{\mathrm{ij}}, a_{i j}=-\frac{1}{2} d_{i j}^{2}$ dan $\boldsymbol{B}=\boldsymbol{H} \boldsymbol{A} \boldsymbol{H}$. Di mana bentuk dari matriks $\boldsymbol{D}$ dan $\boldsymbol{A}$ adalah sebagai berikut:

$\boldsymbol{D}=d_{i j}=\left[\begin{array}{cccccc}d_{11} & d_{12} & \ldots & d_{1 j} & \ldots & d_{1 n} \\ d_{21} & d_{22} & \ldots & d_{2 j} & \ldots & d_{2 n} \\ \vdots & \vdots & & \vdots & & \vdots \\ d_{i 1} & d_{i 2} & \ldots & d_{i j} & \ldots & d_{i n} \\ \vdots & \vdots & & \vdots & & \vdots \\ d_{n 1} & d_{n 2} & \ldots & d_{n j} & \ldots & d_{n n}\end{array}\right]$ dan

$$
\begin{aligned}
& \boldsymbol{A}=a_{i j} \\
& =-\frac{1}{2}\left[\begin{array}{cccccc}
d_{11}{ }^{2} & d_{12}{ }^{2} & \ldots & d_{1 j}{ }^{2} & \ldots & d_{1 n}{ }^{2} \\
d_{21}{ }^{2} & d_{22}{ }^{2} & \ldots & d_{2 j}{ }^{2} & \ldots & d_{2 n}{ }^{2} \\
\vdots & \vdots & & \vdots & & \vdots \\
d_{i 1}{ }^{2} & d_{i 2}{ }^{2} & \ldots & d_{i j}{ }^{2} & \ldots & d_{i n}{ }^{2} \\
\vdots & \vdots & & \vdots & & \vdots \\
d_{n 1}{ }^{2} & d_{n 2}{ }^{2} & \ldots & d_{n j}{ }^{2} & \ldots & d_{n n}{ }^{2}
\end{array}\right]
\end{aligned}
$$

Matrix $\boldsymbol{D}$ adalah Euclid jika dan hanya jika matriks adalah semidefinit positif. Jika $\boldsymbol{D}$ adalah matriks jarak dari $a$ data matriks $\boldsymbol{X}$, maka $\boldsymbol{B}=\boldsymbol{H} \boldsymbol{A H}$.

\section{Mencari Stimulus Coordinat}

Stimulus Coordinat dari tiap-tiap stimulus menunjukkan posisi dalam space. Sebagai contoh, di dalam dua dimensi, misalnya $\left(x_{11}, x_{12}\right)$ adalah koordinat dari stimulus 1 dan $\left(x_{21}, x_{22}\right)$ adalah koordinat dari stimulus 2. Tujuan dari Multidimensional Scaling adalah untuk mencari koordinat titik-titik dalam ruang Euclidian dari matriks jarak yang tersedia.

Misalkan koordinat $n$ titik dalam ruang euclid dimensi $p$ adalah $x_{i}(i=1, \cdots, n)$, di mana $x_{i}\left(x_{i 1}, x_{i 2}, \cdots x_{i p}\right)^{T}$. Jarak euclid antara titik ke- $i$ dan ke- $j$ adalah : $d_{i j}^{2}=\sum_{k=1}^{p}\left(x_{i k}-x_{j k}\right)^{2}$

Secara singkat algoritma classical scaling sebagai berikut :

1. Menentukan koefisien ketakmiripan $\left(\delta_{r t}\right)$

2. Mencari matriks $\boldsymbol{A}=\left[-\frac{1}{2} \delta_{i j}^{2}\right]$

3. Mencari matriks $\boldsymbol{B}=\left\lfloor a_{i j}-a_{i}-a_{j}+a\right\rfloor$,

4. Mencari eigen values $\lambda_{1}, \ldots, \lambda_{\mathrm{n}-1}$ dan eigen vector $\mathrm{v}_{1}, \ldots, \mathrm{v}_{\mathrm{n}-1}$ yang kemudian dinormalkan sehingga $v_{i}^{T} v_{i}=\gamma_{i} \lambda \mathrm{i}$. Jika B tidak semi definit positif ( beberapa eigen values bernilai negatif), maka terdapat 2 pilihan, pilihan 1 adalah membuang eigen values yang bernilai negatif dan melanjutkan proses. Pilihan ke 2 adalah menambahkan suatu konstanta c pada koefisien ketakmiripan sebagai berikut $\delta_{i j}=\delta_{i j}+c\left(1-\delta^{i j}\right)$ dan kembali ke langkah 2. 
5. Memilih jumlah dimensi yang tepat. Dapat menggunakan $\frac{\sum_{i=1}^{p} \lambda_{i}}{\sum(\text { eigen values positif })}$

6. Menentukan koordinat $\mathrm{n}$ titik pada ruang euclid dimensi $p$ dengan $x_{i j}=v_{i j}(i=1, \cdots, n ; j=1, \cdots, p)$.

\section{MDS berskala non-metrik}

MDS non-metrik mengasumsikan bahwa datanya adalah kualitatif (skala nominal dan skala ordinal). Pada kasus ini perhitungan kriteria adalah untuk menghubungkan nilai ketidaksamaan suatu jarak ke nilai ketidaksamaan yang terdekat. Program MDS non-metrik menggunakan transformasi monoton (sama) ke data yang sebenarnya sehingga dapat dilakukan operasi aritmatika terhadap nilai ketidaksamaannya, untuk menyesuaikan jarak dengan nilai urutan ketidaksamaannya.

\section{METODOLOGI}

Tulisan ini merupakan hasil penelitian aplikasi atau terapan. Penelitian ini dilakukan mulai pada bulan November 2016 sampai Maret 2017. Jenis data yang digunakan dalam penelitian ini adalah data sekunder karena data yang dikelola merupakan hasil dari kumpulan data produksi padi yang diperoleh langsung dari:

1. Kantor Badan Pusat Statistik Provinsi Sulawesi Selatan;

2. Kantor Dinas Pertanian;

3. BMKG; dan instansi terkait lainnya.

Variabel yang digunakan ialah atribut-atribut yang mempengaruhi produktivitas padi, atribut tersebut dibagi kedalam tiga segi yaitu ekologi, ekonomi, dan sosial budaya.

Tabel 2 Variabel Produktivitas Padi

\begin{tabular}{|c|ll|}
\hline Segi & \multicolumn{1}{|c|}{ Variabel } \\
\hline \multirow{4}{*}{ Ekologi } & 1. & Luas Panen (Ha) \\
& 2. & Puso Padi (Hektar) \\
& 3. & Curah Hujan $\left(\mathrm{mm}^{3}\right)$ \\
& 4. & Produksi Padi (Ton) \\
\hline \multirow{3}{*}{ Ekonomi } & 1. & Jumlah Penduduk Miskin \\
& (Jiwa) \\
& 2. & Produk Domestik Regional \\
\hline
\end{tabular}

\begin{tabular}{|l|ll|}
\hline \multicolumn{1}{|c|}{ Segi } & \multicolumn{1}{c|}{ Variabel } \\
\hline & 3. & Bruto PDRB (Juta Rp) \\
\hline $\begin{array}{l}\text { Sosial } \\
\text { Budaya }\end{array}$ & 1. & Jumlah Penduduk (Jiwa) \\
\hline
\end{tabular}

Berdasarkan hasil yang ingin dicapai dengan menggunakan metode Multidimensional Scaling maka dibutuhkan pengolahan data dengan langkah-langkah berikut.

1. Memvisualisasikan produktivitas padi

a. Menganilisis data

b. mengubah tabel data dalam bentuk matriks

c. Membuat matriks jarak $\boldsymbol{D}\left(d_{i j}=\delta_{i j}=d_{24 \times 24}\right)$

d. Mencari Matriks $\boldsymbol{A}\left(a_{i j}\right)$

$$
a_{24 \times 24}=-\frac{1}{2} d_{i j}{ }^{2}
$$

e. Mencari matriks $\boldsymbol{B}=\boldsymbol{H} \boldsymbol{A} \boldsymbol{H}$

$$
\boldsymbol{B}=\left(\boldsymbol{I}-\frac{1}{n} \mathbf{1}\right) \boldsymbol{A}\left(\boldsymbol{I}-\frac{1}{n} \mathbf{1}\right)
$$

f. Menentukan Stimulus Coordinate dengan mencari eigen values dan eigen vectors.

g. Menghitung Euclidean distance disparitis antar Kabupaten/Kota dari stimulus koordinat yang dihasilkan.

h. Menguji validitas stimulus koordinat dengan menghitung nilai stress.

i. Menentukan jumlah dimensi dari nilai stress.

j. Menginterpretasikan peta persepsi yang telah diperoleh dari analisis multidimendional scaling dengan melihat validitas dari nilai stress dan nilai $R^{2}$ yang dihasilkan.

2. Menentukan variabel yang mendukung

a. Melakukan analisis multidimensional scaling

b. Memperhatikan variabel yang memiliki posisi stimuli berdekatan dengan objek pada peta spasial.

c. Menginterpretasikan hasil.

\section{PEMBAHASAN}

Banyaknya dimensi yang digunakan pada peta spasial ialah 2 dimensi berdasarkan metode 
scree-elbow. Nilai stress yang dihasilkan adalah sebesar 0.01172. Berdasarkan Kruskal nilai tersebut berarti bahwa model MDS yang digunakan sangat baik bahkan mendekati sempurna. Sedangkan nilai $R^{2}$ yang diperoleh sebesar 0.9994 atau 99\% yang menunjukkan bahwa model Multidimensional scaling yang digunakan baik.

1. Visualisasi produktivitas padi berdasarkan

Kabupaten/Kota di Provinsi Sulawesi selatan berdasarkan hasil gambar 1 berikut:

Gambar 1. Peta Spasial stimulus configuration Euclidean distance model untuk setiap objek

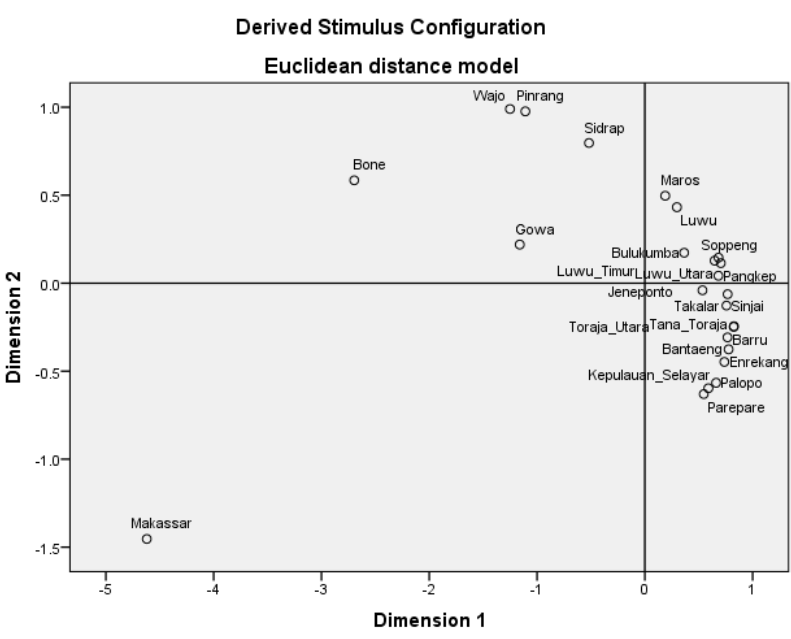

Berikut kelompok Kabupaten/Kota yang memiliki kemiripan produktivitas padi berdasarkan variabel yang digunakan hasil dari beberapa tahap transformasi.

a. Kelompok I adalah Kepulauan Selayar, Kabupaten Bantaeng, Kabupaten Jeneponto, Kabupaten Takalar, Kabupaten Sinjai, Kabupaten Pangkep, Kabupaten Soppeng, Kabupaten Barru, Kabupaten Enrekang, Kabupaten Tana Toraja, Kabupaten Luwu Utara, Kabupaten Luwu Timur, Kabupaten Toraja Utara, Kota Parepare, dan Kota Palopo. Kelompok ini merupakan kelompok Kabupaten/Kota yang memiliki tingkat produktivitas padi yang sedang

b. Kelompok II adalah Kabupaten Bulukumba, Kabupaten Maros, dan Kabupaten Luwu. Tingkat produktivitas padi pada kelompok Kabupaten ini adalah sedang. c. Kelompok III adalah Kabupaten Wajo, Kabupaten Sidrap, dan Kabupaten Pinrang. Tingkat produktivitas padi pada kelompok Kabupaten ini adalah sedang.

d. Kelompok IV adalah Kabupaten Gowa dengan tingkat produktivitas padi sedang.

e. Kelompok V adalah Kabupaten Bone dengan tingkat produktivitas padi sedang.

f. Kelompok VI adalah Kota Makassar dengan tingkat produktivitas padi rendah.

Pengelompokan Kabupaten/Kota ini berdasarkan hasil dari beberapa proses transformasi persamaan yang dipeoleh menggunakan analisis Multidimensional Scaling. Oleh sebab itu, tingkat kategori produktivitas padi (Ton/Ha) memiliki perbedaan setiap kelompoknya.

1. Variabel produktivitas padi yang mendukung Kabupaten/Kota yang ada di Provinsi Sulawesi Selatan

Gambar 2 Penamaan Dimensi pada Peta Spasial stimulus configuration Euclidean distance model

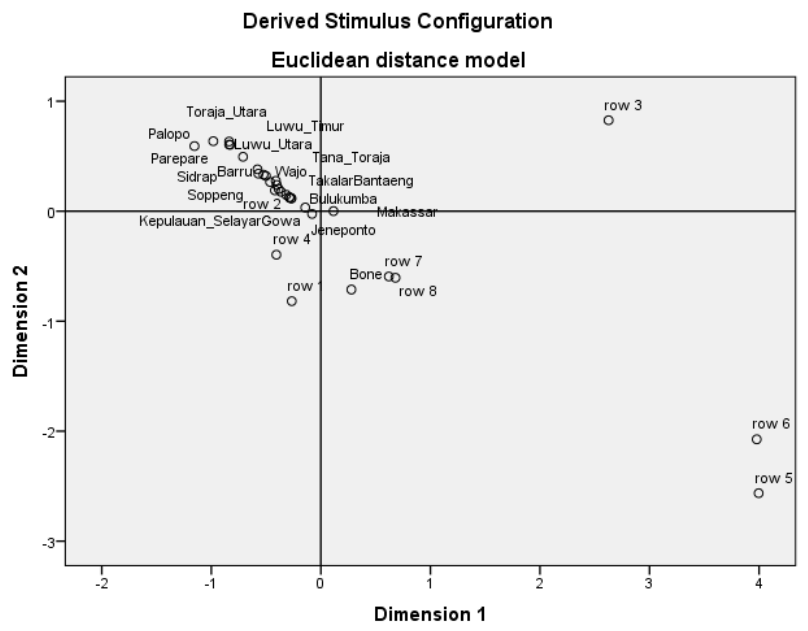

Peta di atas dapat diinterpretasikan menggunakan pendekatan subyektif. Variabel luas panen (row 1), produksi padi (row 4), jumlah penduduk (row 7), dan jumlah rumah tangga (row 8) berada dekat denganKabupaten Bone. Hal ini menunjukkan bahwa Kabupaten Bone berpotensial besar memiliki produktivitas padi yang tinggi dibandingkan dengan Kabupaten/Kota lain di provinsi Sulawesi Selatan. Untuk seluruh Kabupaten/ Kota selain kabupaten Bone terlihat mengapit variabel puso padi (row 2). Sedangkan varia- 
bel curah hujan (row 3), jumlah penduduk miskin (row 5) dan PDRB (row 6) berada jauh atau memiliki jarak yang besar dari gerombolan objek pada peta stimuli. Hal ini menunjukkan bahwa ketiga variabel tersebut tidak berpengaruh secara penuh untuk mendukung produktivitas padi di Provinsi Sulawesi Selatan. Adapun variabel yang mendukung produktivitas padi adalah luas panen $\left(\mathrm{X}_{1}\right)$, puso padi $\left(\mathrm{X}_{2}\right)$, produksi padi $\left(\mathrm{X}_{4}\right)$, jumlah penduduk $\left(\mathrm{X}_{7}\right)$ dan jumlah rumah tangga $\left(\mathrm{X}_{8}\right)$.

\section{DAFTAR PUSTAKA}

[1] Badan Pusat Statistik Provinsi Sulawesi Selatan. 2016. Provinsi Sulawesi Selatan Dalam Angka 2016. Makassar: BPS.

[2] Rencher, Alvin C. and William F. Christensen. 2012. "Methods Of Multivariate Analysis Third Edition". Canada: JohnWiley \& Sons.
[3] Timm, Neil H. 2002. Applied Multivariate Analysis. New York : Springer.

[4] Tiro, Muhammad Arif, Sukarna dan Aswi. 2010. Statistika Deskriptif Peubah Banyak. Makassar: Andira Publisher.

[5] Santosa, Purbayu Budi dan Muliawan Hamdani. 2007. Statistika Deskriptif dalam Bidang Ekonomi dan Niaga. Jakarta: Erlangga.

[6] Sastraatmadja, Entang. 1991. Ekonomi Pertanian Indonesia: Masalah, Gagasan, dan Strategi. Bandung: Angkasa.

[7] Supranto, J. 2010. Analisis Multivariat: Arti dan Interpretasi Edisi Kedua. Jakarta: Rineka Cipta.

[8] Purwandari, Titi dan Yuyun Hidayat. 2015. Identifikasi Negara-Negara yang Memiliki Kemiripan dengan Indonesia Dalam Konteks Krisis Beras Menggunakan Multidimensional Scaling, Laporan Hasil Penelitian. Bandung: Universitas Padjadjaran. 